\title{
Effect of Therapeutic Dose X Rays on Mechanical and Chemical Properties of Esthetic Dental Materials
}

\author{
Adriana Dibo da Cruz**, Mário Alexandre Coelho Sinhoreti, Gláucia Maria Ambrosano ${ }^{\text {, }}$

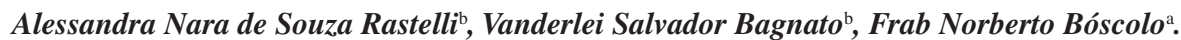 \\ a Piracicaba Dentistry School, UNICAMP, \\ Av. Limeira, 901, Areião, CP 52, 13414-018 Piracicaba-SP, Brazil \\ ${ }^{\mathrm{b}}$ São Carlos Physics Institute, Optics Group, USP, \\ Av. Trabalhador Sãocarlense, 400, CP 369, 13560-970 São Carlos - SP, Brazil
}

Received: June 6, 2008; Revised: September 1, 2008

\begin{abstract}
The aim of this study was to investigate the influence of therapeutic dose $\mathrm{X}$ rays on the microhardness $(\mathrm{MH})$ and degree of conversion (DC) of two different esthetic restorative dental materials. The materials were photo-activated with a LED light-curing unit using three cure-times: 5, 20 and 40 seconds. The photo-activation was carried out in two distinct periods: before and after irradiation with doses of 5, 35 and 70 Gy, from a $6 \mathrm{MV}$ $\mathrm{X}$ rays beam. In accordance with the methodology used, it was conclude that a therapeutic dose does not have a detrimental effect on the photoinitiator molecules, because the photo-activation occurred after they were irradiated. When the irradiation was applied before photo-activation, the materials showed $\mathrm{MH}$ improvement, but when photo-activation was performed after irradiation, there was less improvement. However, there was no correlation between MH and DC. Thus, a therapeutic dose applied to cured material can promote linking and breaking of chain bonds in a non-linear way.
\end{abstract}

Keywords: ionizing radiation, radiotherapy, spectroscopy, Fourier transform infrared, dental materials

\section{Introduction}

During the last few decades, there have been substantial improvements in the optimization of malignant disease treatment ${ }^{1,2}$, and nowadays radiotherapy, an important part of many cancer treatments, could be indicated for patients.

But depending on the location of a head or neck cancer, inevitably, several different healthy tissues can be included in the radiotherapy portals and will receive a relatively high dose per fraction ${ }^{2,3}$. In addition to the undisputed anticancer effects of ionizing irradiation, they will cause damages in all tissues located in the field of radiation. But each irradiated normal tissue will usually show specific reactions to radiotherapy varying from acute, transient to late effects ${ }^{1}$.

However, together with healthy tissue, the dental restorations may be irradiated during fractionation and could receive a significant amount of the radiation dose $\mathrm{e}^{1,2}$. Little is known about the direct exposure of ionizing radiation on dental materials ${ }^{4-10}$, and the exposure results are still unclear ${ }^{9}$. In studies where high-energy ionizing radiations were directly applied on dental materials, as gamma ${ }^{6-8,10}$ or electron radiation ${ }^{4,6}$, some mechanical properties of these dental materials changed proportionally to the increase of the radiation dose.

As patients will certainly have a variety of intraoral dental restorative materials, any interactive effects between the incident $\mathrm{X}$ radiation with such dental materials during their radiotherapy will be clinically significant if the mechanical and chemical properties of the materials were adversely affected.

Therefore, considering that intraoral esthetic restorations can be exposed to ionizing radiations during radiotherapy, the aim of this study was to investigate the influence of a therapeutic dose $\mathrm{X}$ rays on the microhardness $(\mathrm{MH})$ and degree of conversion (DC) of different resin composites.

\section{Experimental Procedures}

Two different commercially available esthetic restorative materials, Filtek $\mathrm{Z}^{250}{ }^{\mathrm{TM}}$ resin composite material (3M/ESPE, St. Paul,
MN, USA) and Fill Magic Flow ${ }^{\circledR}$ flowable resin composite material (Vigodente SA, Rio de Janeiro, RJ, Brazil) were selected for this study. The selected materials show different applicability. The Filtek $\mathrm{Z}^{250^{\mathrm{TM}}}$ is a definitive restorative material to replace anterior and posterior teeth with bigger quantity of inorganic filler zirconia/silica ( $\pm 60 \%$ volume without silane treatment) with a particle size range from 0.01 to 3.5 microns. The Fill Magic Flow ${ }^{\circledR}$ has more viscosity as it has smaller quantity of inorganic filler $( \pm 40 \%)$ with a particle size of 0.7 microns and is used mainly as a definitive preventive restoration of pits and fissures. For each material, 105 disks ( $3 \mathrm{~mm}$ in diameter by $1 \mathrm{~mm}$ thick) were prepared. The specimens of all materials were made using molds of stainless steel rings between mylar strips and glass slides to achieve uniformly smooth surfaces. The molds were placed under pressure of $1 \mathrm{~kg}$ from the top to remove excess material.

Three photo-activation times were used. 1) 5 seconds: a lower time than proposed by the manufacturer, representing insufficient photo-activation time; 2) 20 seconds: the indicated time in the manufacturers' instructions of each material; 3) 40 seconds: a higher time than proposed by the manufacturer. For photo-activation a LED light-curing unit, Lec 1000 (MMoptics, São Carlos, SP, Brazil), with light intensity of $1 \mathrm{~W} . \mathrm{cm}^{-2}$, was used. The photo-activation was carried out in two distinct periods: before (cured-irradiated groups - $\mathrm{CI}$ ) and after (uncured-irradiated groups - UI) the therapeutic dose X rays radiation exposures. The exposure factors were: $\mathrm{X}$ ray doses of 5, 35 and 70 Gy from a Clinac ${ }^{\circledR} 600$ Linear Accelerator (Varian Medical Systems, Palo Alto, CA, USA), with a $6 \mathrm{MV}$ beam.

The $\mathrm{X}$ ray exposures were performed with specimens in their respective molds, without pressure from the top, only the mylar strips. The plastic strips and molds were removed: a) after photoactivation of the UI groups and $b$ ) after $X$ ray exposures of the CI groups. The photo-activation of the UI groups was performed immediately after the $\mathrm{X}$ ray exposures process. The control group 
was only photo-activated for 5, 20 or 40 seconds, without the $\mathrm{X}$ ray exposures process.

The specimens were made in accordance to one of the 3 groups as follow: Control Groups, C-5, C-20, C-40; cured-irradiated group, CI-5-5, CI-20-5, CI-40-5, CI-5-35, CI-20-35, CI-40-35, CI-5-70, CI-20-70, CI-40-70; and uncured-irradiated group, UI-5-5, UI-20-5, UI-40-5, UI-5-35, UI-20-35, UI-40-35, UI-5-70, UI-20-70, UI-40-70.

Afterwards, the specimens were packed into light-proof boxes without humidity at $25^{\circ} \mathrm{C}\left( \pm 2{ }^{\circ} \mathrm{C}\right)$. The humidity was controlled by dehydrated silica.

\subsection{Microhardness analysis}

A Knoop diamond in an HMV-2 (Shimadzu Corporation, Nakagyo-ku, Kyoto, Japan) microhardness tester was used under a $490.3 \mu \mathrm{N}$ load, during 10 seconds. For each specimen, 3 indentations were made randomly on the top surface. The long diagonal of Knoop indentations was measured through the eyepiece of the optical microscope of the HMV-2 microhardness tester at 50x magnification, immediately after indentation, by the same appraiser.

In the UI groups only one KHN measurement was performed, 24 hours after the photo-activation. On the other hand, in the CI groups, two MH measurements were performed, one 24 hours after the photo-activation and the other 24 hours after $\mathrm{X}$ ray exposure. For a statistical analysis, however, only the second $\mathrm{MH}$ measurement of the CI groups was considered. The first measurement was used to assess the homogeneity of the manufacturing technique of the specimens in comparison with the control group. The $\mathrm{MH}$ measurements data for a statistical analysis were collected in the individual groups, always 24 hours after the last experimental procedure. The period of 24 hours was established between each experimental procedure and their analysis trying to evaluate the material in more stable state.

The statistical analysis was performed by the Dunnett test to assess differences in the average value of each experimental group and their respective control group; and ANOVA with Tukey test to find differences between the CI and UI groups comparing the photoactivation times and $\mathrm{X}$ ray doses. The significance level in all tests was $5 \%(\mathrm{p}=0.05)$.

\subsection{Fourier transform-infrared (FTIR) spectroscopy analysis}

The specimens were triturated. $0.1 \mathrm{~g}$ of the triturated material was added to $0.9 \mathrm{~g}$ of $\mathrm{KBr}$, then mixed in an agate-mixing bowl and compressed by a hydraulic press under $10 \mathrm{t}$ for 60 seconds to make pellets.

To measure the degree of conversion, the pellets were attached to holding device in the spectrophotometer (Bomen, model MB - 102, Quebec, Canada). For this technique, the pellets were prepared and analyzed after 24 hours. Fourier transform infra-red spectroscopy (FTIR) spectra of both uncured and cured samples were analyzed using an accessory of diffuse reflectance. The measurements were recorded in absorbance operating under the following conditions: 32 scans, $4 \mathrm{~cm}^{-1}$ resolution, 4000 to $300 \mathrm{~cm}^{-1}$ wavenumber.

The acquired FTIR spectra of each material were computed from tables from the OriginPro 7.5 SRO ${ }^{\circledR}$ (OriginLab Corporation, Northampton, MA, USA) software.

The percentage of unreacted carbon-carbon double bonds ( $\% \mathrm{C}=\mathrm{C}$ ) was determined by the ratio of absorbance intensities of the aliphatic $\mathrm{C}=\mathrm{C}\left(\right.$ peak at $1638 \mathrm{~cm}^{-1}$ ) against internal standard of the aromatic C-C (peak at $1608 \mathrm{~cm}^{-1}$ ) before and after photo-activation of the specimen. This experiment was carried out in triplicate. The degree of conversion was determined by subtracting the $\% \mathrm{C}=\mathrm{C}$ from $100 \%$, according to the formula:

$$
(\%) D C=1-\frac{\left(1638 \mathrm{~cm}^{-1} / 1608 \mathrm{~cm}^{-1}\right) \text { cured }}{\left(1638 \mathrm{~cm}^{-1} / 1608 \mathrm{~cm}^{-1}\right) \text { uncured }} \times 100
$$

The correlation between $\mathrm{MH}$ and DC were analyzed by the Pearson coefficient of correlation.

\section{Results and Discussion}

The MH average values and statistical analysis of the Filtek $\mathrm{Z} 250^{\mathrm{TM}}$ material were shown in Table 1 . There were statistically significant differences $(\mathrm{p}<0.05)$ in CI groups which showed a decrease of $\mathrm{MH}$ when compared to the control group by the Dunnett test. The decrease of $\mathrm{MH}$ occurred due to the increase of the radiation dose in those groups photo-actived for a longer time. On the other hand, in the UI groups the MH increased in those groups photo-actived for a shorter time. The increase of the photo-activation time was the main contributor of the $\mathrm{MH}$ improvement, showing statistically significant differences $(\mathrm{p}<0.05)$ with the Tukey test. However, the $\mathrm{MH}$ improvements due to the increase of the photo-activation were expected once the photo-activation of 5 seconds was shorter than the one recommended by the manufacturer of the materials. In the $\mathrm{CI}$ groups the application of radiation promoted a decrease of $\mathrm{MH}$,

Table 1. Averages of microhardness and standard deviation of the Filtek $\mathrm{Z} 250^{\mathrm{TM}}$ material.

\begin{tabular}{|c|c|c|c|c|c|c|c|}
\hline \multirow{3}{*}{$\begin{array}{l}\text { Photo-activation } \\
\text { time (seconds) }\end{array}$} & \multicolumn{7}{|c|}{ Radiation dose (Standard deviation) } \\
\hline & \multirow{2}{*}{$\frac{\text { Control }}{0 \mathrm{~Gy}}$} & \multicolumn{3}{|c|}{ Cured-irradiated groups } & \multicolumn{3}{|c|}{ Uncured-irradiated groups } \\
\hline & & 5 Gy & $35 \mathrm{~Gy}$ & $70 \mathrm{~Gy}$ & $5 \mathrm{~Gy}$ & $35 \mathrm{~Gy}$ & $70 \mathrm{~Gy}$ \\
\hline \multirow[t]{3}{*}{5} & 59.99 & 53.38 & 53.77 & 50.72 & 63.13 & 68.84 & 66.20 \\
\hline & $(4.16)$ & $(7.46)$ & $(4.54)$ & $(4.30)$ & $(6.81)$ & $(2.97)$ & $(3.77)$ \\
\hline & $\mathrm{a}$ & A a & $\mathrm{A}$ a & $* \mathrm{~A} \mathrm{a}$ & $£ \mathrm{~A}$ a & $£ \mathrm{~A}$ a & $* £ \mathrm{~A}$ a \\
\hline \multirow[t]{3}{*}{20} & 74.80 & 55.46 & 61.66 & 63.67 & 72.76 & 79.68 & 82.00 \\
\hline & $(7.86)$ & $(1.53)$ & $(6.60)$ & $(1.55)$ & $(8.07)$ & $(2.57)$ & $(5.85)$ \\
\hline & $\mathrm{b}$ & $* \mathrm{~A}$ a & $* \mathrm{~A} a b$ & $* \mathrm{Ab}$ & $£ \mathrm{~A}$ a & $£ \mathrm{~A}$ a & $* £ \mathrm{Ab}$ \\
\hline \multirow[t]{3}{*}{40} & 78.09 & 62.38 & 64.16 & 62.77 & 73.34 & 77.17 & 85.99 \\
\hline & (3.06) & $(2.45)$ & $(4.81)$ & $(3.20)$ & (8.97) & (5.14) & (7.34) \\
\hline & $\mathrm{b}$ & $* \mathrm{~A} \mathrm{a}$ & $* \mathrm{Ab}$ & $* \mathrm{Ab}$ & $£ \mathrm{~A} \mathrm{a}$ & $£ \mathrm{~B}$ a & $£ \mathrm{~B} \mathrm{~b}$ \\
\hline
\end{tabular}

*The value differed from control by Dunnett test $(\mathrm{p}<0.05)$; $£$ There were differences in microhardness values between cured-irradiated and uncured-irradiated groups $(\mathrm{p}<0.0001)$. The cured-irradiated groups showed smaller microhardness values at all doses radiation and for all photo-activation times when compared with UI groups. Values with the same capital letter in the line into of the same group comparing radiation dose and same lower case letter in column comparing photo-activation time are not significantly different (ANOVA and Tukey test, $\mathrm{p}>0.05$ ). 
observed in Figure 1, while in UI groups the contrary occurred (Figure 2). The increase of the MH and the photo-activation time followed the logarithmic function. However, independent of the change of $\mathrm{MH}$, the DC remained almost invariable in the CI group (Figure 3) as well as in the UI group (Figure 4). There is no correlation between $\mathrm{MH}$ and $\mathrm{DC}\left(\mathrm{r}^{2}=0.2212\right)$.

The results of the present study do not agree with those of others studies ${ }^{4,-8,10}$ in which linear function between $\mathrm{MH}$ improvement and radiation dose increase was found. In the present study, this could suggest that the ionizing radiation had an additional effect on $\mathrm{MH}$

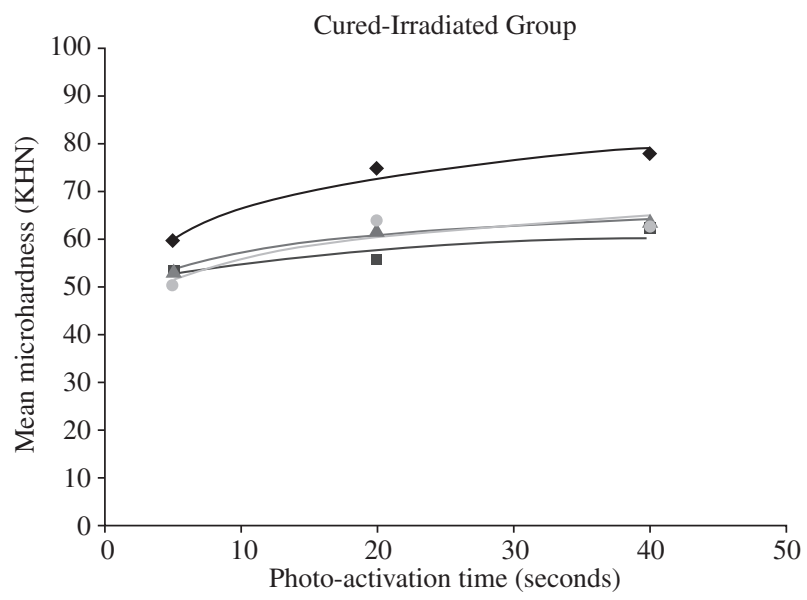

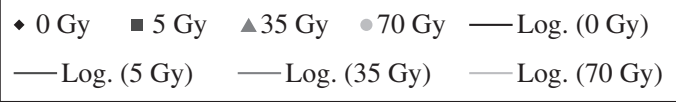

Figure 1. Regression analysis of microhardness averages of the Filtek Z250 ${ }^{\mathrm{TM}}$ material to cured-irradiated groups in accordance with radiation dose as a function of the photo-activation time.

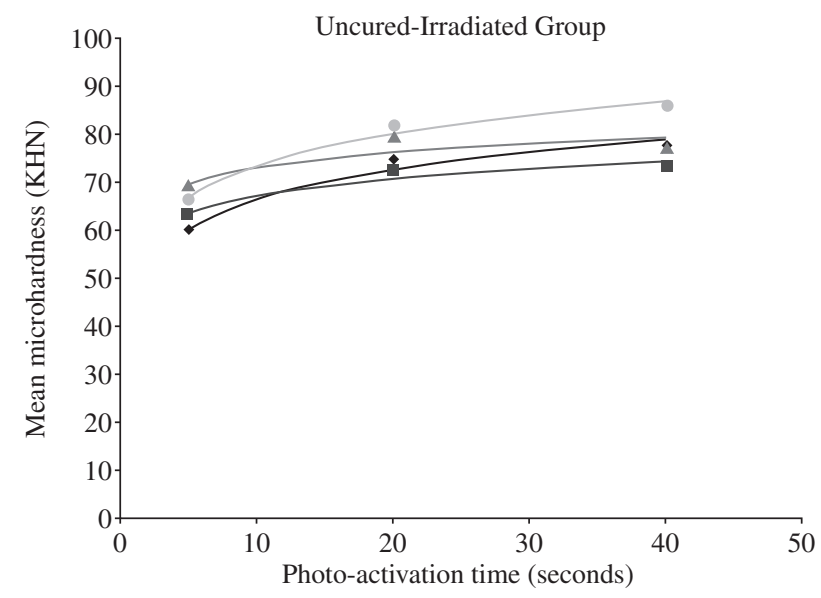

$$
\begin{aligned}
& \text { • } 0 \text { Gy } \backsim 5 \text { Gy } \triangle 35 \mathrm{~Gy} \text { • } 70 \mathrm{~Gy} \text { - Log. (0 Gy) } \\
& \text { — Log. (5 Gy) - Log. (35 Gy) - Log. (70 Gy) }
\end{aligned}
$$

Figure 2. Regression analysis of microhardness averages of the Filtek Z250 ${ }^{\mathrm{TM}}$ material to uncured-irradiated groups in accordance with radiation dose as a function of the photo-activation time. in the UI groups, promoting excitation before the photo-activation process. This excitation could improve the link among chains after the cure ${ }^{8}$. On the other hand, in the CI groups the ionizing radiation could break established bonds in the cure process which would result in a decrease in $\mathrm{MH}$. The DC values shown in the present study for Filtek $\mathrm{Z}_{250}{ }^{\mathrm{TM}}$ are compatible with values related in literature ${ }^{11}$; values close to $50 \%$ represent a good DC. There is a controversy about correlation between $\mathrm{MH}$ and DC. While some authors ${ }^{12-13}$ indicate that there is correlation, others ${ }^{14,15}$ indicate that there is not. In the present study no correlation was observed, as the radiation

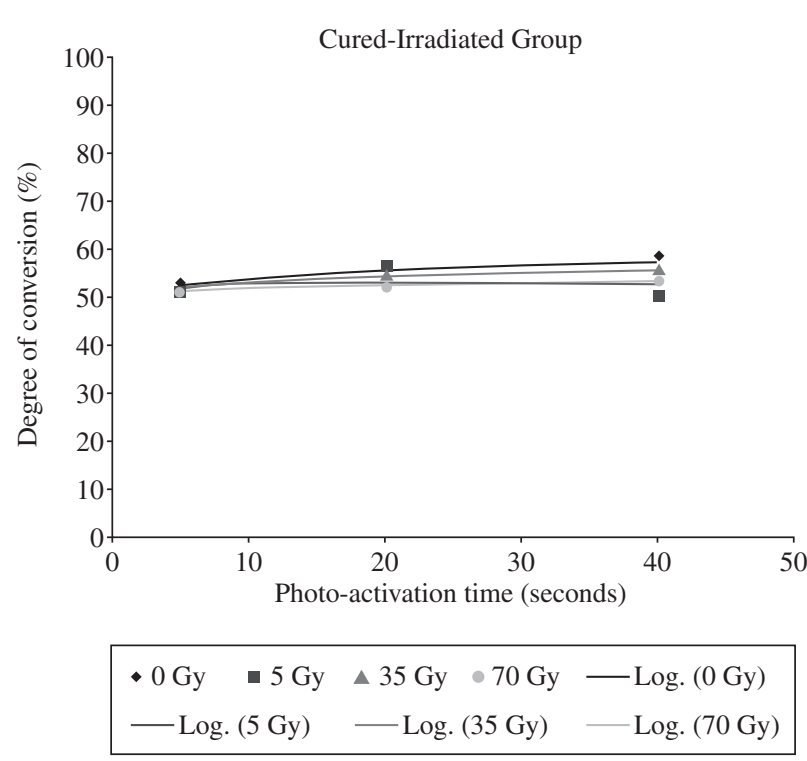

Figure 3. Regression analysis of degree of conversion of the Filtek $\mathrm{Z} 250^{\mathrm{TM}}$ material to uncured-irradiated groups in accordance with radiation dose as a function of the photo-activation time.

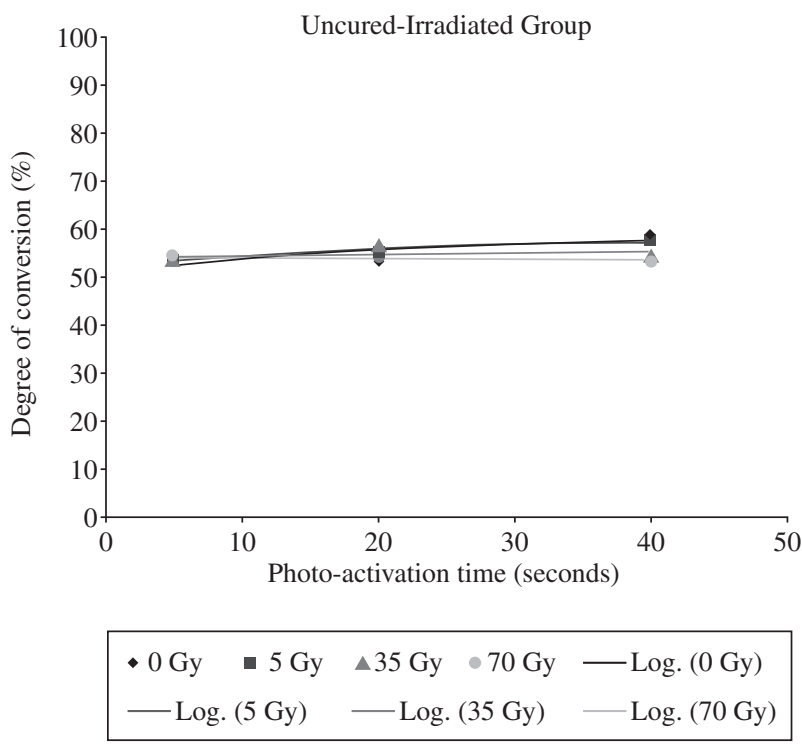

Figure 4. Regression analysis of degree of conversion of the Filtek $\mathrm{Z} 250^{\mathrm{TM}}$ material to cured-irradiated groups in accordance with radiation dose as a function of the photo-activation time. 
promoted little change in DC but in $\mathrm{MH}$ the alterations were more expressive.

The MH average values and statistical analysis of the Fill Magic Flow ${ }^{\circledR}$ material were shown in Table 2 . There were statistically significant differences $(\mathrm{p}<0.05)$ in $\mathrm{MH}$ of several groups, in $\mathrm{CI}$ as well as in UI, when they were compared to the control group by the Dunnett test. In different groups which were photo-actived for a shorter time a decrease on the MH was observed, while those photo-actived for a longer time an increase was observed. Furthermore, both the photo-activation time and the radiation dose contributed to $\mathrm{MH}$, once that statistically significant differences $(\mathrm{p}<0.05)$ with Tukey test were observed. The MH improvement due to increase of the photo-activation time was expected once the time of 5 seconds was also used. On the other hand, $\mathrm{MH}$ improvement due to an increase of the radiation dose in this case was also observed (Figures 5 and 6). However, independent of the changes of $\mathrm{MH}$, the DC remained almost invariable in the CI group (Figure 7) as well as in the UI group
(Figure 8). The increase of the radiation dose did not contribute to an increase in DC. Thus the correlation between MH and DC $\left(r^{2}=0.2603\right)$ was not observed.

For the Fill Magic Flow ${ }^{\circledR}$ material, the DC values were lower than for Filtek $\mathrm{Z} 250^{\mathrm{TM}}$ because the flowable resin composite material has a greater proportion of ionomer glass and lower proportion of Bis-GMA which promote high chain mobility, which may limit conversion. Thus DC values around $25 \%$ can be considered as a good DC for Fill Magic Flow ${ }^{\circledR}$ material ${ }^{16-17}$.

These results indicated that the ionizing radiation promote simultaneously the linking and the breaking of bonds, but the predominance of one specific event over an other depended on the structural configuration of each material at the moment of irradiation, before or after photo-activation. When the irradiation occurred before the photo-activation, excitation points were created in the organic matrix of the material ${ }^{8}$, and due to high mobility among these chemical groups more bond links occurred resulting in an increase of $\mathrm{MH}$. On

Table 2. Microhardness averages and standard deviations of the Fill Magic Flow ${ }^{\circledR}$ material.

\begin{tabular}{|c|c|c|c|c|c|c|c|}
\hline \multirow{3}{*}{$\begin{array}{l}\text { Photo-activation } \\
\text { time (seconds) }\end{array}$} & \multicolumn{7}{|c|}{ Radiation dose (Standard deviation) } \\
\hline & \multirow{2}{*}{$\begin{array}{c}\text { Control } \\
0 \mathrm{~Gy} \\
\end{array}$} & \multicolumn{3}{|c|}{ Cured-irradiated groups } & \multicolumn{3}{|c|}{ Uncured-irradiated groups } \\
\hline & & $5 \mathrm{~Gy}$ & $35 \mathrm{~Gy}$ & $70 \mathrm{~Gy}$ & 5 Gy & $35 \mathrm{~Gy}$ & 70 Gy \\
\hline \multirow[t]{3}{*}{5} & 9.66 & 9.78 & 9.43 & 15.66 & 12.68 & 10.43 & 11.31 \\
\hline & $(0.14)$ & $(0.75)$ & $(0.21)$ & $(2.22)$ & $(1.42)$ & $(0.91)$ & $(0.91)$ \\
\hline & $\mathrm{a}$ & $\mathrm{A}$ a & A a & $* \mathrm{~B}$ a & $* £ \mathrm{~A} \mathrm{a}$ & $£ \mathrm{~A} \mathrm{a}$ & $* £ \mathrm{~A}$ a \\
\hline \multirow[t]{3}{*}{20} & 15.87 & 10.90 & 15.56 & 18.17 & 14.43 & 19.06 & 20.36 \\
\hline & $(0.36)$ & $(0.68)$ & $(0.22)$ & $(0.84)$ & $(1.86)$ & $(1.16)$ & $(2.18)$ \\
\hline & $\mathrm{b}$ & $* \mathrm{~A}$ ab & $\mathrm{B} \mathrm{b}$ & $\mathrm{Cb}$ & $£ \mathrm{~A}$ a & $* £ \mathrm{~B} b$ & $* £ \mathrm{~B} \mathrm{~b}$ \\
\hline \multirow[t]{3}{*}{40} & 18.48 & 12.16 & 16.26 & 21.42 & 13.82 & 20.03 & 19.23 \\
\hline & $(0.86)$ & $(2.56)$ & (1.29) & $(2.02)$ & $(3.41)$ & $(2.48)$ & $(0.71)$ \\
\hline & $\mathrm{c}$ & $* \mathrm{~A} \mathrm{~b}$ & $\mathrm{~B} \mathrm{~b}$ & $* \mathrm{Cc}$ & $* \mathrm{~A} \mathrm{a}$ & $£ \mathrm{~B} \mathrm{~b}$ & $£ \mathrm{~B} \mathrm{~b}$ \\
\hline
\end{tabular}

*The value differed from control by Dunnett test $(\mathrm{p}<0.05)$; $£$ There were differences in microhardness values between cured-irradiated and uncured-irradiated groups $(\mathrm{p}<0.0001)$. Values with the same capital letter in the line into of the same group comparing radiation dose and same lower case letter in column comparing photo-activation time are not significantly different (ANOVA and Tukey test, $\mathrm{p}>0.05$ ).

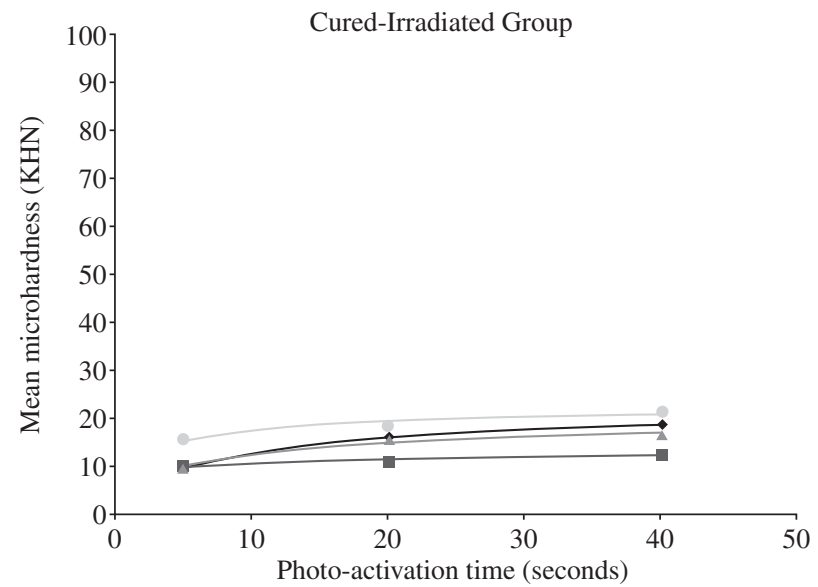

$$
\begin{aligned}
& \text { - } 0 \text { Gy - } 5 \text { Gy } \triangle 35 \text { Gy } \quad 70 \text { Gy — Log. (0 Gy) } \\
& \text { —Log. (5 Gy) — Log. (35 Gy) — Log. (70 Gy) }
\end{aligned}
$$

Figure 5. Regression analysis of microhardness averages of the Fill Magic Flow ${ }^{\circledR}$ material to cured-irradiated groups in accordance with radiation dose as a function of the photo-activation time.

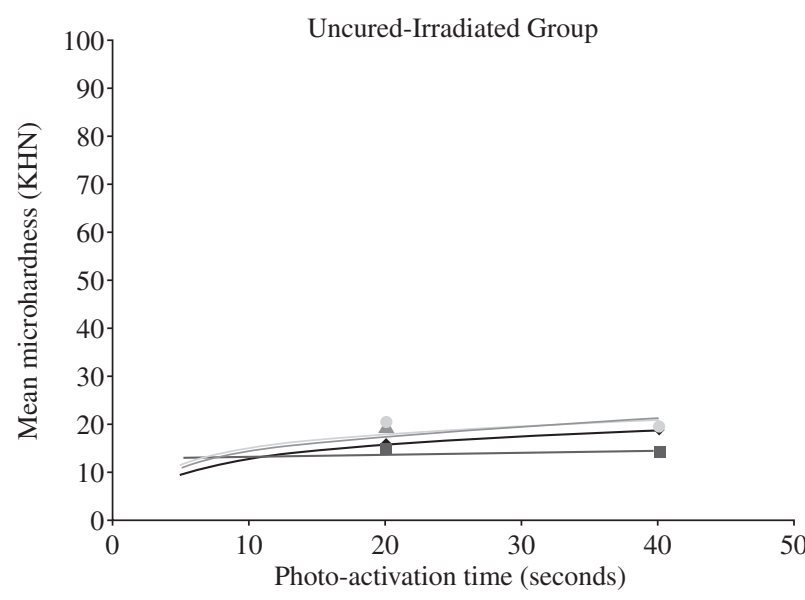

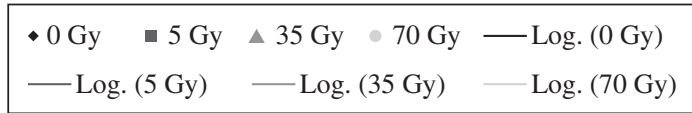

Figure 6. Regression analysis of microhardness averages of the Fill Magic Flow $^{\circledast}$ material to cured-irradiated groups in accordance with radiation dose as a function of the photo-activation time. 


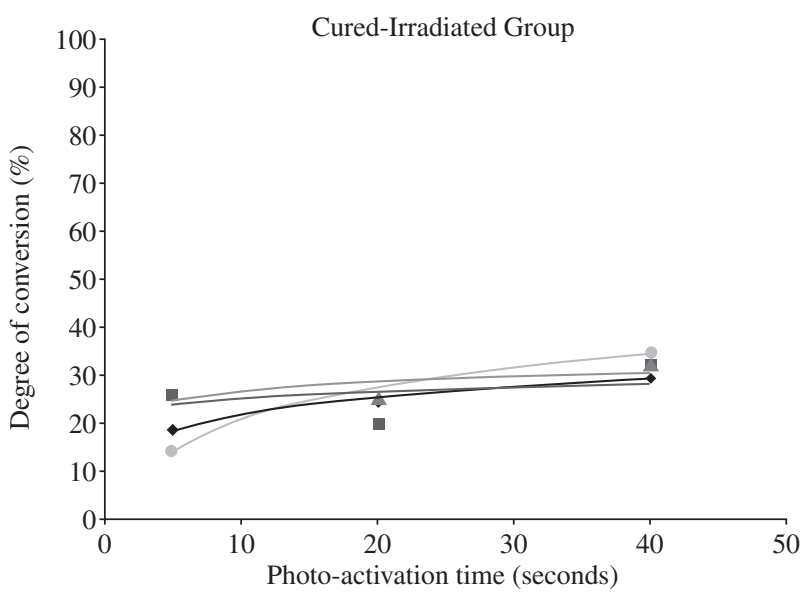

$$
\begin{aligned}
& \text { • } 0 \text { Gy } \text { - } 5 \text { Gy } \text { × } 35 \text { Gy • } 70 \text { Gy — Log. (0 Gy) } \\
& \text { —Log. (5 Gy) — Log. (35 Gy) - Log. (70 Gy) }
\end{aligned}
$$

Figure 7. Regression analysis of degree of conversion of the Fill Magic Flow ${ }^{\circledR}$ material to uncured-irradiated groups in accordance with radiation dose as a function of the photo-activation time.

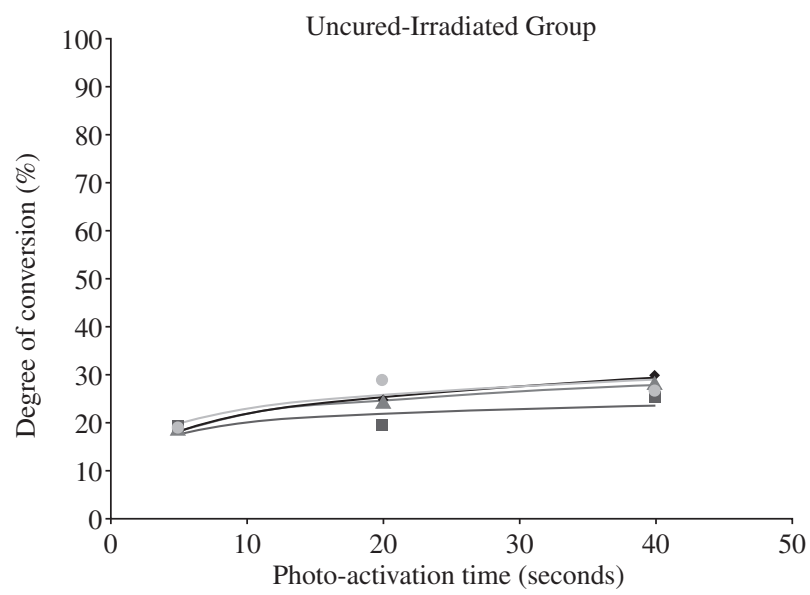

$$
\begin{array}{lll}
\bullet 0 \mathrm{~Gy} \quad 5 \mathrm{~Gy} & \Delta 35 \mathrm{~Gy} \quad \text { 70 Gy } & -\log .(0 \mathrm{~Gy}) \\
-\log .(5 \mathrm{~Gy}) & -\log .(35 \mathrm{~Gy}) & -\log .(70 \mathrm{~Gy})
\end{array}
$$

Figure 8. Regression analysis of degree of conversion of the Fill Magic Flow ${ }^{\circledR}$ material to cured-irradiated groups in accordance with radiation dose as a function of the photo-activation time.

the other hand, when the irradiation occurred after photo-activation, there were also excitations, but as the chains were already linked, the predominance was the breaking of bonds due to high radiation energy and rigid structural configuration ${ }^{9}$.

Little is known about the effect of ionizing radiation on dental material $^{4-10}$. In the few studies that exist ${ }^{4-10}$, the effects of radiation were related to mechanical properties, indicating that there was a linearity between the increase of the radiation dose and the reaction ${ }^{5-8,10}$. In the present study, it was not possible to suggest the same linear- ity, even when the radiation dose was similar to that used in some studies $^{5,10}$. In others studies the used radiation doses were higher than the ones used in the present study $y^{4,6-7}$, doses that were not compatible to the ones used in radiotherapy of head and neck tumors ${ }^{1-3}$. Thus, the lack of linearity between the radiation dose and the increase in reactions found in this study may not be related to the radiation dose used, even if the effect induced by the ionizing radiation is accumulative $^{2}$. The lack of linearity may be related to the absorption process of high-energy radiation ${ }^{6}$ by the dental resin composite. This process may produce excitation and ionization in organic matrixes of the dental material creating coupled reactive species that may be chemical reagents starters ${ }^{8}$. These starters may create new chains or stabilize existent chains, which would increase the MH of the material but would not increase the DC.

The radiation did not change the photo-initiator molecule, as the cure occurred, in a similar way, even after the irradiation process. The sensibility of the photo-initiator molecule is around $465 \mathrm{~nm}^{18}$, and the $\mathrm{X}$ radiation in the therapeutic dose had a wavelength of approximately $0.005 \mathrm{~nm}$. The authors Von Fraunhofer et al. ${ }^{10}$ (1989) maintained that the increase in $\mathrm{MH}$ occurred due to the gamma radiation which is capable of increasing the DC in photo-activated dental materials. However, this supposition was not confirmed through chemical analyses, because in their study only mechanical analyses were made. The present study cannot corroborate this, since the $\mathrm{MH}$ increase did not depend on DC, so other chemical groups must be responsible for the increase in $\mathrm{MH}$. However, the mechanical change may not be correlated directly to the effects of radiation or same created chemical reagents. The effects of the ionizing radiation on dental materials is still not completely known, and further studies must be conducted to seek other responses correlating chemical and mechanical properties.

Furthermore, it must be emphasized that the results of an "in vitro" study are not directly applicable to radiation effects on dental materials in the oral environment. In the oral cavity there are different agents which influence in a more complex manner than the experimental ones used in this study ${ }^{9}$. These agents can also cause aging by changing the mechanical and chemical behavior of the dental materials.

\section{Conclusion}

In accordance with the methodology used, the conclusion reached was that a therapeutic dose does not have a detrimental effect on the photoinitiator molecules, because the photo-activation occurred after they were irradiated. There was no correlation between $\mathrm{MH}$ and DC. When the irradiation was applied before photo-activation, the materials showed improved $\mathrm{MH}$, and when photo-activation was performed after irradiation, there was less improvement. Thus, a therapeutic dose applied to cured material can promote linking and breaking of chain bonds. Therefore it is indicated that the confection of a new dental restoration with a photo-cured composite resin should be made after the end of radiotherapy and never before, and old restorations should be attended and replaced when necessary.

\section{Acknowledgements}

This study is part of a $\mathrm{PhD}$ degree thesis, in Dental Radiology of the Oral Diagnosis Department (FOP-UNICAMP). The authors thank "Servidores de Cana de Piracicaba" Hospital for authorizing the use of the linear accelerator, and for placing their radiotherapy technicians at the authors' disposition for this study. They also thank all students of the USP Optics Group (IFSC-USP) for their technical support during experimental procedures; and the FUNCAMP for providing financial support for this study. 


\section{References}

1. Anscher MS, Chen L, Rabbani Z, Kang S, Larrier N, Huang H. et al. Recent progress in defining mechanisms and potential targets for prevention of normal tissue injury after radiation therapy. Int. J. Radiat. Oncol. Biol. Phys. 2005; 62:255-259.

2. Binger T, Seifert H, Blass G, Bormann KH, Rücker M. Dose inhomogeneities on surfaces of different dental implants during irradiation with high-energy photons. Dentomaxillofac Radiol. 2008; 37(3):149-153.

3. Jham BC, Reis PM, Miranda EL, Lopes RC, Carvalho AL, Scheper MA, Freire AR. Oral health status of 207 head and neck cancer patients before, during and after radiotherapy. Clin Oral Investig. 2008; 12(1):19-24.

4. Behr M, Martin R, Faltermeier A, Handel G. Electron beam irradiation of dental composites. Dent Mater. 2005; 21(9):804-810.

5. Curtis-Jr PM, Farman AG, Von-Fraunhofer JA. Effects of gamma radiation on the in vitro wear of composite restorative materials. J. Dent. 1991; 19(4):241-244.

6. Haque S, Takinami S, Watari F, Khan MH, Nakamura M. Radiation effects of carbon ions and gamma ray on UDMA based dental resin. Dent Mater J. 2001 Dec; 20(4):325-338.

7. Hsiue GH, Chang HL. The effects of radiation-modified silica and monomeric diluents on the properties of dental composite resins. Angew Makromol Chem. 1993; 209:63-77.

8. Langel MCM, Louro SRW. High-level dosimetry by radiation induced free radicals in dental restorative resins. Nucl Instrum Methods Phys Res Sect B-Beam Interact Mater Atoms. 1986; 16(4-5):419-423.

9. Schulzea KA, Marshalla SJ, Ganskyb SA, Marshalla GW. Color stability and hardness in dental composites after accelerated aging. Dent Mater. 2003 Nov; 19(7):612-619.
10. Von-Fraunhofer JA, Curtis-Jr P, Sharma S, Farmam AG. The effects of gamma radiation on the properties of composite restorative resins. $J$. Dent. 1989 Aug; 17(4):177-83.

11. Young AM, Rafeeka SA, Howlett JA. FTIR Investigation of monomer polymerization and polyacid neutralization kinetics and mechanisms in various aestethic dental restorative materials. Biomaterials $2004 \mathrm{Feb}$; 25(5):823-833.

12. Rode KM, Kawano Y, Turbino ML. Evaluation of curing light distance on resin composite microhardness and polymerization. Oper Dent. 2007 Nov-Dec; 32(6):571-578.

13. Santos GB, Medeiros IS, Fellows CE, Muench A, Braga RR. Composite depth of cure obtained with QTH and LED units assessed by microhardness and micro-Raman spectroscopy. Oper Dent. 2007 Jan-Feb; 32(1):79-83.

14. Calheiros FC, Kawano Y, Stansbury JW, Braga RR. Influence of radiant exposure on contraction stress, degree of conversion and mechanical properties of resin composites. Dent Mater. 2006 Sep; 22(9):799-803.

15. Knobloch LA, Kerby RE, Clelland N, Lee J. Hardness and degree of conversion of posterior packable composites. Oper. Dent. 2004 Nov-Dec; 29(6):642-649.

16. Baroudi K, Saleh AM, Silikas N, Watts DC. Shrinkage behaviour of flowable resin-composites related to conversion and filler-fraction. J. Dent. 2007; 35(8):651-655.

17. Neves AD, Discacciati JA, Oréfice RL, Yoshida MI. Influence of the power density on the kinetics of photopolymerization and properties of dental composites. J Biomed Mater Res B Appl Biomater. 2005; 72(2):393-400.

18. Ye Q, Wang Y, Williams K, Spencer P. Characterization of photopolymerization of dentin adhesives as a function of light source and irradiance. J Biomed Mater Res Part B: Appl Biomater 2007; 80B:440-446. 